\title{
Extended-spectrum beta-lactamase-producing Escherichia coli in chickens from small-scale (backyard) poultry farms in Maiduguri, Nigeria
}

\author{
Iliya Dauda Kwoji ${ }^{1}$, Jasini Athanda Musa ${ }^{1}$, Nubwa Daniel ${ }^{2}$, Dauda Luka Mohzo ${ }^{3}$, Asinamai Athliamai Bitrus ${ }^{4}$,
} Abiodun Andrew Ojo ${ }^{1}$ and Kingsley Uwakwe Ezema ${ }^{5}$

1. Department of Veterinary Microbiology, Faculty of Veterinary Medicine, University of Maiduguri, P.M.B 1069, Nigeria;

2. Department of Veterinary Pharmacology and Toxicology, Faculty of Veterinary Medicine, University of Maiduguri, P.M.B 1069, Nigeria; 3. Department of Veterinary Pathology, Faculty of Veterinary Medicine, University of Maiduguri, P.M.B

1069, Nigeria; 4. Department of Veterinary Public health, Faculty of Veterinary Science, Chulalongkorn University, 10330

Pathumwan Bangkok, Thailand; 5. Veterinary Teaching Hospital, University of Maiduguri, P.M.B 1069, Nigeria.

Corresponding author: Iliya Dauda Kwoji; e-mail: kojdail28@unimaid.edu.ng

Co-authors: JAM: jasiniamusa@gmail.com, ND: nubwadaniel@gmail.com, DLM: daudamohzo@gmail.com, AAB: abasinamai@gmail.com, AAO: andy482@yahoo.com, KUE: kuwakwe8@gmail.com

Received: 15-01-2019, Accepted: 27-02-2019, Published online: 27-03-2019

doi: 10.14202/IJOH.2019.26-30 How to cite this article: Kwoji ID, Musa JA, Daniel N, Mohzo DL, Bitrus AA, Ojo AA, Ezema KU. Extended-spectrum beta-lactamase-producing Escherichia coli in chickens from small-scale (backyard) poultry farms in Maiduguri, Nigeria. Int J One Health 2019;5:26-30.

\begin{abstract}
Aim: This study investigated the occurrence of extended-spectrum beta-lactamase (ESBL)-producing Escherichia coli in chickens from small-scale (backyard) commercial poultry farms in Maiduguri.

Materials and Methods: A total of 96 cloacal swab samples were collected. This comprised of 24 samples each from broiler chicks, pullets, layers, and broilers (adults). The samples were examined for the presence of $E$. coli using conventional microbiological culture and biochemical tests. The pure E. coli isolates were screened for ESBL production by culturing onto Brilliance ${ }^{\mathrm{TM}}$ ESBL agar. Isolates that showed positive reactions with production of bluish or pinkish colonies were tested for susceptibilities against some selected beta-lactam antibiotics which include cefotaxime $(30 \mu \mathrm{g})$, ceftriaxone $(30 \mu \mathrm{g})$, cefpodoxime $(10 \mu \mathrm{g})$, aztreonam $(30 \mu \mathrm{g})$, and ceftazidime $(30 \mu \mathrm{g})$. Isolates that exhibited resistance to any two or three of the antibiotics were selected and confirmed by combination disk diffusion method with ceftazidime $(30 \mu \mathrm{g})$ and cefotaxime $(30 \mu \mathrm{g})$ alone and in combination with clavulanic acid $(30 \mu \mathrm{g} / 10 \mu \mathrm{g})$.
\end{abstract}

Results: The total occurrence of $E$. coli was $67.6 \%$ (65/96) with the highest occurrence of $83.3 \%$ (20/24) from broiler chicks and least detection of $54.2 \%$ (13/24) from layers. Of this, $32.0 \%$ were ESBL-producing E. coli with the highest detection rate from layers $(38.5 \%)$ and least occurrence from pullets $(26.7 \%)$.

Conclusion: This study revealed the presence of ESBL-producing E. coli in chickens from small-scale commercial poultry farms in Maiduguri, thus indicating that chickens may serve as important reservoirs for the transmission of antimicrobial resistant pathogens to humans through the food chain.

Keywords: antimicrobials, chickens, extended-spectrum beta-lactamase, Escherichia coli, Maiduguri.

\section{Introduction}

The surge in the prevalence of antimicrobial resistance from foodborne pathogens and the natural environment is one of the most significant threats to animals and humans in the $21^{\text {st }}$ century [1-4]. This is due to the narrowing down in the cache of antibiotics both in quantity and quality and due to the gap between antimicrobial resistance and development of antibiotics [5-8]. Food-producing animals are among the most important reservoirs of antimicrobial resistance genes $[1,9,10]$, due partly to the frequent and indiscriminate use of antimicrobial agents as feed additives for prophylaxis and in the treatment of gastrointestinal illness in animals $[4,11]$, thus facilitating the shading of

Copyright: Kwoji, et al. This article is an open access article distributed under the terms of the Creative Commons Attribution 4.0 International License (http://creativecommons.org/licenses/ by/4.0/), which permits unrestricted use, distribution, and reproduction in any medium, provided you give appropriate credit to the original author(s) and the source, provide a link to the Creative Commons license, and indicate if changes were made. The Creative Commons Public Domain Dedication waiver (http:// creativecommons.org/ publicdomain/zero/1.0/) applies to the data made available in this article, unless otherwise stated. resistance genes and pathogenic foodborne bacteria into the environment [12].

The emergence of extended-spectrum beta-lactamase (ESBL)-producing Escherichia coli in humans and animals has gained global notoriety during the past decade. This comes along with a fiery concern of food animals serving as potential reservoirs of ESBL genes. Since ESBL are plasmid coded, their transfer from animals to humans cannot be overemphasized [13]. In addition, some strains of $E$. coli have been observed to play a pivotal role in the spread and maintenance of ESBL genes [14,15]. ESBL act by inactivating beta-lactam antibiotics such as penicillin and third-generation cephalosporins through hydrolysis of their beta-lactam ring. The enzymes are found majorly in Enterobacteriaceae, members of the normal gut flora causing opportunistic to severe bloodstream and urinary tract infections [16-18].

The poultry industry has assumed greater importance in improving employment opportunities and animal food production in Nigeria [19-21]. Earlier reports showed that poultry production accounts for 
about $36.5 \%$ of sources of protein in Nigeria $[22,23]$. However, the viability and growth of this sector is hampered by diseases which have consequently resulted in reduced output in terms of production [12]. In many communities in Nigeria, small-scale poultry farms constitute a large portion of poultry farming activities, and previous studies have reported that this poses a major risk in the dissemination of multidrug-resistant pathogens in the environment [24].

In view of the increasing concerns about ESBLproducing E. coli in food animals and the possible risk that they pose to public health [25], this study was carried out to investigate the presence of ESBLproducing $E$. coli in small-scale poultry farms within Maiduguri.

\section{Materials and Methods}

\section{Ethical approval and informed consent}

The study design was approved by the Animal Ethics Committee of the Faculty of Veterinary Medicine, University of Maiduguri. Also, informed consent from farmers was obtained for the inclusion of their farms in the study.

\section{Sampling}

A total of 96 cloacal swab samples consisting of 24 samples each from broiler chicks, broilers, layers, and pullets were collected and used in this study. The samples were collected from chickens on deep-litter systems in small-scale farms located at Lake Chad, Damboa Road, Mairi, and New GRA wards of Maiduguri. Cloacal swab samples were collected with the aid of pre-labeled sterile swab-sticks dipped in peptone and packed in polystyrene cooler containing ice-packs for immediate transportation to Bacteriology Research Laboratory, Department of Veterinary Microbiology, University of Maiduguri.

\section{Bacterial isolates}

The bottles containing cloacal swabs were incubated for $2 \mathrm{~h}$ at $37^{\circ} \mathrm{C}$ aerobically. After enrichment, the samples were then streaked onto freshly prepared eosin methylene blue (EMB; Oxoid, UK) agar and incubated aerobically at $37^{\circ} \mathrm{C}$ for $24 \mathrm{~h}$. E. coli colonies on EMB with the appearance of very dark and with a metallic green sheen were sub-cultured onto Nutrient Agar (Oxoid, UK) and incubated at $37^{\circ} \mathrm{C}$ for $24 \mathrm{~h}$. The colonies were subjected to gram staining for cellular morphology and a series of biochemical tests according to Jang et al. (2004). Identified E. coli isolates were kept on nutrient agar slant (Oxoid, UK) at room temperature until used.

\section{Antibiotic susceptibility test and confirmation of ESBL production}

Pure E. coli isolates were screened for ESBL production by culturing onto a Brilliance ${ }^{\mathrm{TM}} \mathrm{ESBL}$ agar (Oxoid, UK) a chromogenic screening plate for the detection of ESBL-producing organisms. The plates were then incubated at $37^{\circ} \mathrm{C}$ for $24 \mathrm{~h}$. ESBL-producing $E$. coli were identified by characteristic bluish or pinkish colonies. The ESBL-producing E. coli were tested for susceptibility using disk diffusion method as described by Bauer et al. [26]. The ESBL-producing E. coli were tested against five beta-lactam antibiotics which included cefpodoxime $(10 \mu \mathrm{g})$, ceftazidime $(30 \mu \mathrm{g})$, aztreonam $(30 \mu \mathrm{g})$, cefotaxime $(30 \mu \mathrm{g})$, and ceftriaxone $(30 \mu \mathrm{g})$. The diameters of inhibition zones were measured and interpreted as per the guidelines of the Clinical and Laboratory Standards Institute [27]. All the isolates that showed resistance to any of the two or three cephalosporins were subjected to confirmation for ESBL production using combination disk diffusion method with ceftazidime $(30 \mu \mathrm{g})$ and cefotaxime $(30 \mu \mathrm{g})$ alone and in combination with clavulanic acid $(30 \mu \mathrm{g} / 10 \mu \mathrm{g})$ (Oxoid, Basingstoke, UK). The $E$. coli isolates were phenotypically considered as ESBL producers when there is an increase of $\geq 5 \mathrm{~mm}$ in the size of inhibition zone for antimicrobial agents when tested along with clavulanic (ceftazidime-clavulanic acid or cefotaxime-clavulanic acid) in addition to the initial zones of inhibition when ceftazidime and cefotaxime were tested alone

\section{Statistical analysis}

The data obtained from this study were summarized and presented for descriptive purposes in the form of tables as percentages. Chi-square analysis was used to test for the level of statistical significance in the association of the occurrence of $E$. coli and ESBL-producing $E$. coli from chickens with respect to chicken types and age using GraphPad Instat3 (GraphPad Software, 2365 Northside Dr. Suite 560 San Diego, CA 92108). Relative risk and confidence interval of $95 \%$ were used for the determination of level of statistical significance and the values of $\mathrm{p}<0.05$ was considered statistically significant.

\section{Results}

Table-1 shows the occurrence of E. coli and ESBL-producing $E$. coli in chickens from backyard poultry farms in Maiduguri. The total occurrence of E. coli observed was $67.7 \%(65 / 96)$ with the highest occurrence from broiler chicks $83.3 \%$ (20/24), followed by broiler $70.8 \%(17 / 24)$ and pullet $62.5 \%$ $(15 / 24)$, while the lowest was from layers having $54.2 \%(13 / 24)$. However, this result showed no statistically significant difference in the occurrence of E. coli in chickens based on types and ages $(\mathrm{p}>0.05)$ (Table-2). In the same vein, the total occurrence of ESBL-producing $E$. coli was $32.3 \%(21 / 65)$ with the highest detection rate from layers $38.5 \%(5 / 13)$ followed by broilers $35.3 \%(6 / 17)$ and broiler chicks $30.0 \%(6 / 20)$, while the least occurrence was from pullets $26.7 \%(4 / 15)$ as shown in Table-1. The result of this study also showed no statistically significant difference in the occurrence of ESBL-producing E. coli in chickens based on types and age (Table-3) (p>0.05) (Table-3). The presumptive ESBL-producing $E$. coli isolates were tested for susceptibility against 
Table-1: Occurrence of E. coli and ESBL-producing E. coli in chickens from small-scale poultry farms in Maiduguri.

\begin{tabular}{lccc}
\hline Sample source & Number of sample & \multicolumn{2}{c}{ Number of positive (\%) } \\
\cline { 3 - 4 } & & E. coli & ESBL-producing E. coli \\
\hline Broiler chicks & 24 & $20(83.3)$ & $6(30.0)$ \\
Broiler & 24 & $17(70.8)$ & $6(35.3)$ \\
Pullets & 24 & $15(62.5)$ & $4(26.7)$ \\
Layers & 24 & $13(54.2)$ & $5(38.5)$ \\
Total & 96 & $65(67.7)$ & $21(32.3)$ \\
\hline
\end{tabular}

$\mathrm{ESBL}=$ Extended-spectrum beta-lactamase, E. coli=Escherichia coli

Table-2: Occurrence of $E$. coli in chickens from small-scale poultry farms in Maiduguri based on chicken types and age.

\begin{tabular}{llccccc}
\hline Factors & Level & Number of sample & Prevalence (\%) & p-value & RR & CI \\
\hline Chicken types & Broiler & 24 & 77.1 & REF & NA & NA \\
& Layers & 24 & 58.3 & 0.0808 & 1.321 & $0.9941-1.756$ \\
Age & 44 weeks & 24 & 72.9 & REF & NA & NA \\
& $>4$ weeks & 24 & 62.5 & 0.3826 & 1.167 & $0.8827-1.542$ \\
\hline
\end{tabular}

$\mathrm{RR}=$ Relative risk, $\mathrm{CI}=$ Confidence interval, $E$. coli=Escherichia coli

Table-3: Occurrence of ESBL-producing E. coli in chickens from small-scale poultry farms in Maiduguri based on chicken types and age.

\begin{tabular}{llccccc}
\hline Factors & Level & Number of sample & Prevalence (\%) & p-value & RR & CI \\
\hline Chickens type & Broiler & 37 & 32.4 & REF & NA & NA \\
& Layers & 28 & 32.1 & 0.9803 & 1.009 & $0.4953-2.055$ \\
Age & <4 weeks & 35 & 28.6 & REF & NA & NA \\
& $>4$ weeks & 30 & 33.3 & 0.6674 & 0.7792 & $0.1462-0.4627$ \\
\hline
\end{tabular}

$\mathrm{RR}=$ Relative Risk, $\mathrm{CI}=$ Confidence interval, $\mathrm{ESBL}=$ Extended-spectrum beta-lactamase, $E$. coli=Escherichia coli

aztreonam, cefpodoxime $(10 \mu \mathrm{g})$, ceftazidime, ceftriaxone, and cefuroxime. From the table, highest resistance was recorded against aztreonam $(98.5 \%)$, followed by ceftriaxone $(96.9 \%)$, ceftazidime $(93.8 \%)$, and cefuroxime $(75.4 \%)$, while the least resistance was from cefpodoxime $(67.7 \%)$. In the same manner, the highest susceptibility was recorded against cefpodoxime $(32.3 \%)$ and the least susceptibility was against aztreonam (1.5\%) (Table-4).

\section{Discussion}

In this study, a total of 96 cloacal swab samples were collected from chickens in small-scale poultry farms in Maiduguri and screened for the presence of ESBL-producing E. coli. Total prevalence of $67.7 \%$ of $E$. coli was obtained with the highest occurrence of $83.3 \%$ in broiler chicks. This agrees with the findings of Kegode et al. [28] where a similar occurrence of $E$. coli from chickens was also reported. The finding of this study also showed that the occurrence of $E$. coli in chickens $<4$ weeks of age $(72.9 \%)$ was higher compared to birds of age $>4$ weeks (Table-2). This finding is not in agreement with other previous studies where the authors reported $44 \%$ prevalence of $E$. coli in chicks [29]. The high occurrence of $E$. coli in chicks from this study could be linked to a lack of good sanitary conditions observed in the farm environments during this work. It was noted from this study that most small-scale farmers entrust their farm management to individuals who have little or no formal education and experience in poultry farm practice and
Table-4: Susceptibility of $E$. coli to beta-lactam antibiotics

\begin{tabular}{lcc}
\hline Antibiotics & Resistance (\%) & Susceptible (\%) \\
\hline ATM $(30 \mu \mathrm{g})$ & $64(98.5)$ & $1(1.5)$ \\
CPD $(10 \mu \mathrm{g})$ & $44(67.7)$ & $21(32.3)$ \\
CAZ $(30 \mu \mathrm{g})$ & $61(93.8)$ & $4(6.2)$ \\
CTX $(10 \mu \mathrm{g})$ & $63(96.9)$ & $2(3.1)$ \\
CRO $(30 \mu \mathrm{g})$ & $49(75.4)$ & $16(24.6)$ \\
\hline
\end{tabular}

E. coli=Escherichia coli. ATM=Amoxicillin, $\mathrm{CPD}=$ Cefpodoxime, $\mathrm{CRO}=$ Ceftriaxone, $\mathrm{CAZ}=$ Ceftazidime, CTX $=$ Cefotaxime

therefore give little attention to the hygiene of birds and the environments. Hence, creating a conducive atmosphere for bacterial growth and colonization. In addition, the high occurrence could also be attributed to sampling source and type of samples, and for the fact that $E$. coli is a normal gut flora, [30-32].

In this study, a total occurrence of $32.3 \%$ of ESBL-producing $E$. coli was observed in chickens. Similar prevalence of ESBL-producing E. coli in chickens was also reported in Zambia by Chishimba et al. [6]. This finding is lower than the findings of previous studies [33-35], where higher occurrences of ESBL-producing E. coli were reported in chicken meat. It was also observed from this study that the highest occurrence of ESBL-producing E. coli was from laying birds (layers) (38.5\%). Based on this, it is important to note that layers are normally kept for a longer period and therefore may have prolonged exposure to antibiotics for prophylaxis which might result in the selection of drug-resistant bacterial 
pathogens. However, since no statistically significant difference was observed $(p>0.05)$ in the occurrence of the pathogen in chickens with respect to chicken-types, it implied that both broilers and layers are at risk of harboring the organism when raised under conditions that support the selection of antimicrobial resistant pathogens. The occurrence of ESBL-producing E. coli in broilers is higher than the findings of Shoaib et al. [32] where $7.76 \%$ occurrence rate was reported. Furthermore, results of analysis of the occurrence of ESBL-producing E. coli in chickens based on age showed no statistically significant difference on the occurrence of the organism $(p>0.05)$ which implies that both age groups may be at risk of harboring the pathogens if managed under conditions that promote transmission and acquisition of the organism.

According to our results, E. coli isolates were resistant to aztreonam (98.5\%), ceftriaxone $(96.9 \%)$, ceftazidime $(93.8 \%)$, cefuroxime $(75.4 \%)$, and cefpodoxime $(67.7 \%)$. These findings are in contrast to that of Gundogan and Avci [9] where lower resistance to cefotaxime $(33.3 \%)$, ceftazidime $(8.9 \%)$, and ceftriaxone $(8.9 \%)$ was reported. The high antibiotic resistance among $E$. coli recorded in this present study might be due to uncontrolled administration of antibiotics to chickens.

\section{Conclusion}

The study affirmed the presence of ESBLproducing $E$. coli in chickens from backyard poultry farms in the study area. These isolates also showed a high level of antibiotic resistance to third-generation cephalosporins and the monobactam, aztreonam. This is of serious public health significance since birds are reared in close proximity to human population and may disseminate these resistant pathogens in the environment and in-contact farm personnel.

\section{Authors' Contributions}

IDK, JAM, and AAO conceived and designed the work and put the first draft of the manuscript. ND, DLM, and KUE participated in some field work and data collection. AAB and IDK analyzed the data obtained from the study and contributed to the final draft of the manuscript. All authors read and approved the final manuscript.

\section{Acknowledgment}

This research work was jointly funded by the authors as no external source of funding was obtained. Additionally, some materials and consumables used for the work were provided by the Department of Veterinary Microbiology, University of Maiduguri, Nigeria. The authors duly acknowledged all the technical staff of Bacteriology Research Laboratory, Department of Veterinary Microbiology, University of Maiduguri for their commitment in the conduct of this research.

\section{Competing Interests}

The authors declare that they have no competing interests.

\section{Publisher's Note}

Veterinary World (Publisher of International Journal of One Health) remains neutral with regard to jurisdictional claims in published institutional affiliation.

\section{References}

1. Carattoli A. Animal reservoirs for extended spectrum $\beta$-lactamase producers. Clin Microbiol Infect 2008;14: 117-23.

2. WHO. Global Action Plan on Antimicrobial Resistance; 2015.

3. Kraemer JG, Pires J, Kueffer M, Semaani E, Endimiani A, Hilty $\mathrm{M}$, et al. Prevalence of extended-spectrum $\beta$-lactamase-producing Enterobacteriaceae and MethicillinResistant Staphylococcus aureus in pig farms in Switzerland. Sci Total Environ 2017:603-4.

4. Bitrus AA, Chuanchuen R, Luangtongkum T. Emergence of colistin resistance in extended-spectrum beta-lactamase producing Enterobacteriaceae isolated from food animals and its public health implication: A review. J Adv Vet Anim Res 2018;5:1-1.

5. Rottier WC, Ammerlaan HS, Bonten MJ. Effects of confounders and intermediates on the association of bacteremia caused by extended-spectrum $\beta$-lactamase-producing Enterobacteriaceae and patient outcome: A meta-analysis. J Antimicrob Chemother 2012;67:1311-20.

6. Chishimba K, Hangombe BM, Muzandu K, Mshana SE, Matee MI, Nakajima C, et al. Detection of extended-spectrum beta-lactamase-producing Escherichia coli in market-ready chickens in Zambia. Int J Microbiol 2016;5:5275724.

7. Kluytmans-van den Bergh MF, Rossen JW, BruijningVerhagen PC, Bonten MJ, Friedrich AW, VandenbrouckeGrauls CM, et al. Whole-genome multilocus sequence typing of extended-spectrum-beta-lactamase-producing Enterobacteriaceae. J Clin Microbiol 2016;54:2919-27.

8. Runcharoen C, Raven KE, Reuter S, Kallonen T, Paksanont S, Thammachote J, et al. Whole-genome sequencing of ESBL producing Escherichia coli isolated from patients, farm waste and canals in Thailand. Gen Med 2017;9:81-93.

9. Gundogan N, Avci E. Prevalence and antibiotic resistance of extended-spectrum beta-lactamase (ESBL) producing Escherichia coli and Klebsiella species isolated from foods of animal origin in Turkey. Afr J Microbiol Res 2013;7: 4059-64.

10. Gao L, Tan Y, Zhang X, Hu J, Miao Z, Wei L and Chai T. Emissions of Escherichia coli carrying extended-spectrum $\beta$-lactamase resistance from pig farms to the surrounding environment. Int J Environ Res Pub Health 2015;12: 4203-13.

11. Webster P. The perils of poultry. Can Med Ass 2009;7:1-2.

12. Kwoji ID, Tambuwal FM, Abubakar MB, Yakubu Y, Bitrus AA, Jauro S. Occurrence of methicillin-resistant Staphylococcus aureus in chickens and farm personnel in Sokoto, North-western Nigeria. J Adv Vet Anim Res 2017;4: 255-60.

13. Madec JY, Haenni M, Nordmann P, Poirel L. Extendedspectrum $\beta$-lactamase/AmpC-and carbapenemase-producing Enterobacteriaceae in animals: A threat for humans? Clin Microbiol Infect 2017;23:826-33.

14. Rossolini GM, D'Andrea MM, Mugnaioli C. The spread of CTX-M-type extended-spectrum beta-lactamase. Clin Microbiol Infect 2008;14:33-41.

15. Silvia LM and Jacoby AG. Extended-spectrum 
beta-lactamase. US: Wolters Kluwer Health; 2014.

16. Perez F, Endimiani A, Hujer KM, Bonomo RA. The continuing challenge of ESBL. Curr Opin Pharm 2007;7:459-69.

17. Cantón R, Novais A, Valverde A, Machado E, Peix`e L, Baquero F, et al. Prevalence and spread of extended-spectrum $\beta$-lactamase-producing Enterobacteriaceae in European society. Clin Microbiol Infect Dis 2008;14:144-53.

18. Horton RA, Duncan D, Randall LP, Chappell S, Brunton LA, Warner R, et al. Longitudinal study of CTX-M ESBLproducing E. coli strains on a UK dairy farm. Res Vet Sci2016; 109:107-13.

19. Food and Agricultural Organization (FAO). Statistical Database of Food and Agriculture Organization of the United Nations. Rome, Italy: Food and Agricultural Organization; 1999.

20. Emokaro CO, Akinrinmola FK, Emokpae OP. Economics of backyard poultry farming in Benin City, Edo state, Nigeria. Nig J Agric Food Environ 2016;12:50-5.

21. Mshelia IT, Atsanda NN, Bitrus AA, Adam BM, Fika II, Balami SB, et al. Retrospective study of selected endemic viral diseases of poultry diagnosed in Maiduguri NorthEastern Nigeria. J Anim Health Prod 2016;4:60-4.

22. Maikasuwa MA, Jabo MS. Profitability of backyard poultry farming in Sokoto metropolis, Sokoto state, North-West, Nigeria. Nig J Basic Appl Sci 2011;19:111-5.

23. Gambo HI, Bitrus AA, Adam BM, Goni DM, Kwoji ID, Thliza SJ, et al. Survey of hepatic lesions and incriminating pathogens in rural scavenger chickens in Maiduguri, NorthEastern Nigeria. Adv Anim Vet Sci 2016;4:174-7.

24. Nafarnda WD, Ajayi IE, Shawulu JC. Bacteriological quality of abattoir effluents discharged into water bodies in Abuja, Nigeria. ISRN Vet Sci 2012;5:515689.

25. Anjum MF, Lemma F, Cork DJ, Meunier D, Murphy N, North SE, et al. Isolation and detection of extended-spectrum beta-lactamase (ESBL)-producing Enterobacteriaceae from meat using chromogenic agars and isothermal loop-mediated amplification (LAMP) assays. J Food Sci 2013;78:M1892-8.

26. Bauer AW, Kirby WM, Sherris JC, Turck M. Antibiotic susceptibility testing by a standardized single disk method. Am
J Clin Pathol 1966;45:493-6.

27. Clinical and Laboratory Standards Institute (CLSI): Performance Standards for Antimicrobial Susceptibility Testing; Twenty-Sixth Informational Supplement. CLSI Document M100-S26. Wayne, PA: Clinical and Laboratory Standards Institute; 2016.

28. Kegode RB, Doetkott DK, Khaitsa ML, Wesley IV. Occurrence of Campylobacter species, Salmonella species and generic Escherichia coli in meat products from retail outlets in the Fargo metropolitan area. J Food Saf 2008;28: $111-25$.

29. Abdeltawab AA, Abdelaal SA, Mazied EM, EL-Morsy DL. Prevalence of $E$. coli in broiler chickens in winter and summer seasons by application of PCR with its antibiogram pattern. Benha Vet Med J 2015;29:119-128.

30. Saliu BK, Sule IO, Agbabiaka TO. Comparative study of bacteria in the digestive tract of chicken reared as free rangers and those reared at poultry. Biol Environ Sci J Trop 2012; 9:26-9.

31. Salah-Eldin TA, Hamady GA, Abdel-Moneim MA, Farroh KY, El-Reffaei WH. Nutritional evaluation of Selenium-methionine nanocomposite as a novel dietary supplement for laying hens. J Anim Health Prod 2015;3:64-72.

32. Shoaib M, Kamboh AA, Sajid A, Mughal GA, Leghari RA, Malhi KK, et al. Prevalence of extended-spectrum beta-lactamase producing Enterobacteriaceae in commercial broilers and backyard chickens. Adv Anim Vet Sci 2016;4:209-14.

33. Overdevest I, Willemsen I, Rijnsburger M, Eustace A, $\mathrm{Xu} \mathrm{L}$, Hawkey $\mathrm{P}$, et al. Extended-spectrum $\beta$-Lactamase genes of Escherichia coli in chicken meat and humans, the Netherlands. Emerg Infect Dis 2011;17:1216-22.

34. Beninati C, Reich F, Muscolino D, Giarratana F, Panebianco A, Klein G, et al. ESBL-producing bacteria and MRSA isolated from poultry and turkey products imported from Italy. Czech J Food Sci 2015;33:97-102.

35. Stuart JC, van den MunckhofT, Voets G, Scharringa J, FluitA, Hall ML. Comparison of ESBL contamination in organic and conventional retail chicken meat. Int J Food Microbiol 2012; 154:212-4.

$* * * * * * * *$ 